\title{
Vorwort der deutschen Redaktion
}

Das Problem der Optimierung spielt heute auf vielen Gebieten von Technik, Ökonomie und Naturwissenschaften eine wesentliche Rolle und gewinnt noch an Bedeutung. Dementsprechend wächst auch das Interesse an zusammenfassenden Darstellungen zu diesem Gebiet. Offenbar fehlt aber in deutscher Sprache bisher eine Monographie, die die allgemeinen Gesichtspunkte und Methoden der Optimierung in einer vom speziellen Anwendungsgebiet losgelösten Form in lesbarer und anschaulicher Art und Weise darstellt. Dem Verfasser ist daher für seine sehr durchdachte Einführung in die Optimierungspraxis zu danken, und es ist zu hoffen, daß auch der deutsche Leser aus der Beschäftigung mit dem Buch seinen Nutzen zieht. Der deutschen Ausgabe liegt, ebenso wie der französischen, der lediglich an einer Stelle geänderte englische Text zugrunde. 
